\title{
Correction to: Psychometric evaluation of the Encouragement Character Strength Scale in a Chinese sample
}

\author{
Tao Wang ${ }^{1} \cdot$ Ting Zhang ${ }^{1} \cdot$ Wenlong $\mathrm{Mu}^{1} \cdot{\mathrm{Xue} \mathrm{Li}^{1,2}}^{1}$
}

๑) Springer Science+Business Media, LLC, part of Springer Nature 2021

\section{Correction to: Current Psychology (2021) \\ https://doi.org/10.1007/s12144-020-01161-w}

The original version of this article unfortunately contained several a mistake in the affiliation section. Thus, this erratum is presented to fix the error.

The original article has been corrected.

Publisher's note Springer Nature remains neutral with regard to jurisdictional claims in published maps and institutional affiliations.

The original article can be found online at https://doi.org/10.1007/ s12144-020-01161-w.

\section{Xue Li}

xueli@zuel.edu.cn

1 School of Economics and Management, Wuhan University, Bayi Road, Wuchang District, Wuhan, Hubei, People's Republic of China

2 School of Foreign Studies, Zhongnan University of Economics and Law, 182 Nanhu Avenue, East Lake High-tech Development Zone, Wuhan, Hubei, People's Republic of China 